Research Journal of Applied Sciences 13 (7): 414-424, 2018

ISSN: $1815-932 \mathrm{X}$

(C) Medwell Journals, 2018

\title{
Improving Urban Coverage of Bike-Sharing Systems Through Accessibility Models
}

\author{
${ }^{1}$ Juan David Zuluaga, ${ }^{1}$ Diego Alexander Escobar and ${ }^{2}$ Carlos Alberto Moncada \\ ${ }^{1}$ Universidad Nacional de Colombia, Colombia, Cra 27\#64-60 Off. I-408, \\ 170004 Manizales, Colombia \\ ${ }^{2}$ Universidad Nacional de Colombia, Ciudad Universitaria Block 214 Off. 417, \\ 11001000 Bogota, Colombia
}

\begin{abstract}
This analysis was developed in Manizales, Colombia. The main purpose of this research is to evaluate the influence of increasing the number of stations of a bike-sharing program using accessibility models and the benefits in terms of travel time for population. The travel time spent to arrive at a bike station is calculated, obtaining a spatial coverage represented by isochrones curves using the average speed by foot which is affected by the slope of the streets. In order to get an approach of the influence of the location of bike stations, the results are compared with the socioeconomic level of the city, evaluating which level is induced the most.
\end{abstract}

Key words: Accessibility, coverage, sustainability, transport system, urban planning, obtaining, Colombia

\section{INTRODUCTION}

Manizales is the capital of Caldas (one of the smallest Departments of Colombia), lying on the Colombian central mountain range. It has an extension of $508 \mathrm{~km}^{2}$ and the urban roads have about $749 \mathrm{~km}$. (Anonymous, 2010) (Fig. 1). The city has a bike-sharing program called "Manizales en Bici"; it has been working for 2 years and it has 135 bikes distributed in eight stations (Fig. 2). In this study, the location of the current stations is evaluated using a geospatial analysis. Furthermore, socio-demographic information is analysed to establish quantitative comparisons between all the socioeconomic levels and two new proposals of the location of more bike stations are evaluated to observe how increasing coverage enhance the system performance.

Bike sharing programs have existed for 60 years, however in the last decade they have gained popularity worldwide as a revolutionary and alternative mode of transport (Shaheen et al., 2010). The operation of the system is based in providing docking stations in several points of the city, allowing people to get a bicycle for loan for a short period of time. A bike sharing program is efficient when the usage of the bicycles is about 4-8 times per day. Low than 4 uses/bike refers to low cost-benefit and more than 8 uses/bike refers to low availability of bikes in peak periods (Gauthie et al., 2013).

The success of a bike sharing program relies on providing in the majority of origin and destinations docking stations with enough amount of bikes (Wang et al., 2016). (Broach et al., 2012) emphasizes on the location and distribution of docking stations, improving the accessibility to all users of any socioeconomic level. The classical definition of accessibility is attributed to Hansen (1959) "The potential of opportunities for interaction.". Accessibility can demonstrate technically the potential interaction between different geographical points, aiming at identifying the ease or difficulty of reaching a destination through available infrastructure and means of transport (Geurs and Eck, 2001) with different kinds of reasons as commuting (Holly), migration (Kotavaara et al., 2012; Spiekerman and Neubauer, 2002), capital flows (Brocker et al., 2010) or potential production (Gutierrez et al., 2010) (Fig. 3 and 4).

Furthermore, an accessibility analysis is regarded as a key instrument (Papa et al., 2016) to develop the welfare of a region (Jiang and Levinson, 2017). Many researchers have attempted to find the relationship between accessibility and economic development (MacKinnon et al., 2008; Ribeiro and Silva, 2011; Rietveld and Nijkamp, 1992; Vickerman et al., 1999) sustainability (Cheng et al., 2007), supply sand retail site location (Suarez-Vega et al., 2012), optimal location of equipment (Frade and Ribeiro, 2015; Garcia-Palomares et al., 2012a; Rybarczyk and Wu, 2010), disparity between private and public transportation accessibility (Benenson et al., 201 1; Jaramillo et al., 2012;

Corresponding Author: Juan David Zuluaga, Universidad Nacional de Colombia, Cra 27\#64-60 Off. I-408, 170004 Manizales, Colombia 
Res. J. Applied Sci., 13 (7): 414-424, 2018
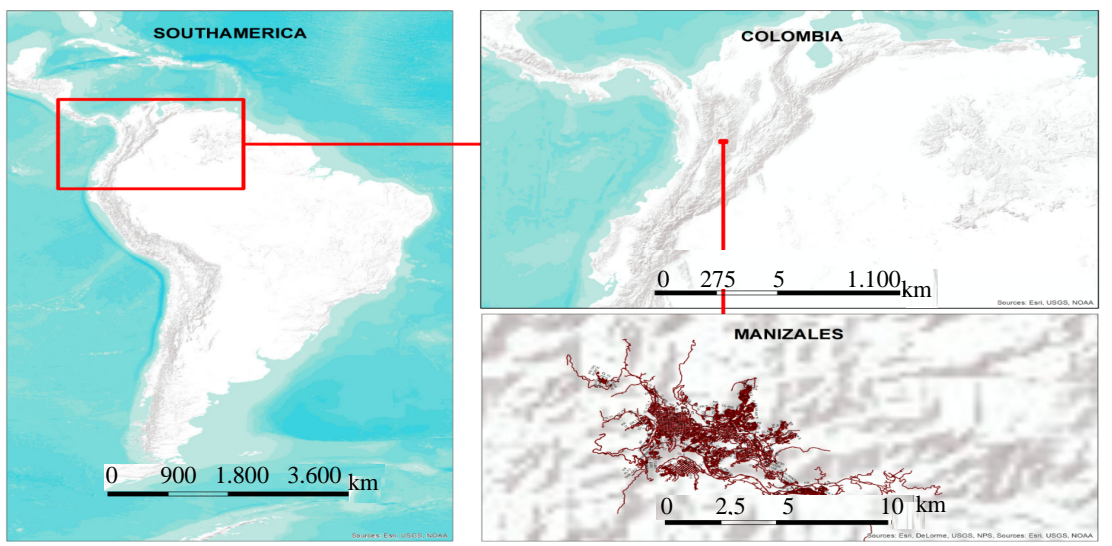

Fig. 1: Geographical location of Manizales city (Researchers from ESRI)

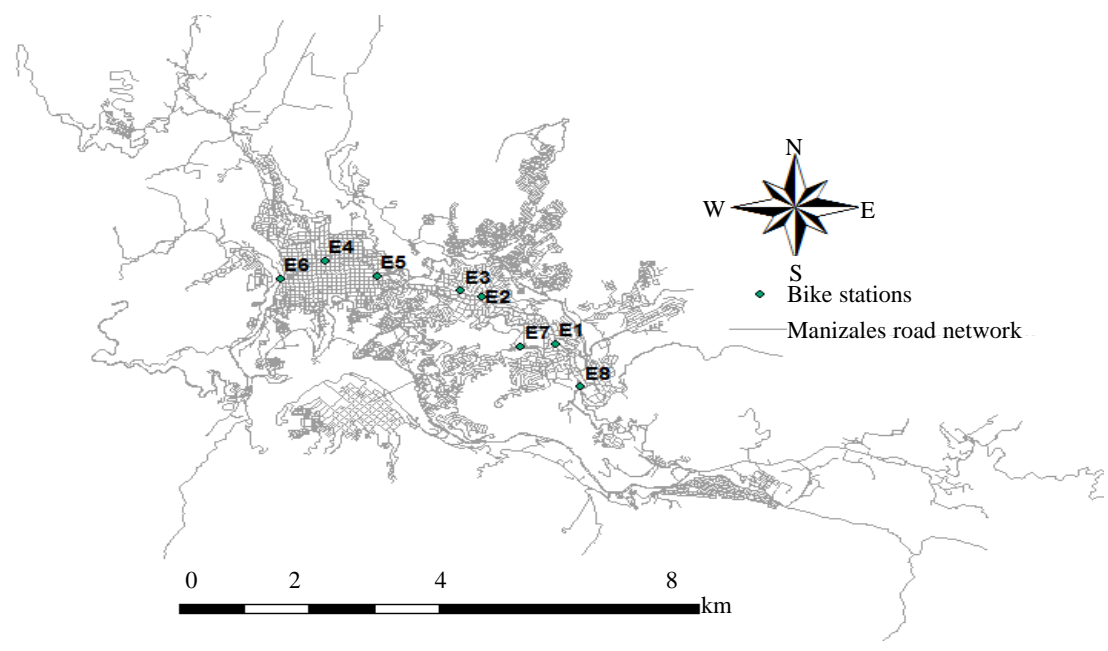

Fig. 2: Bike stations of Manizale's bike-sharing system current scenario researchers

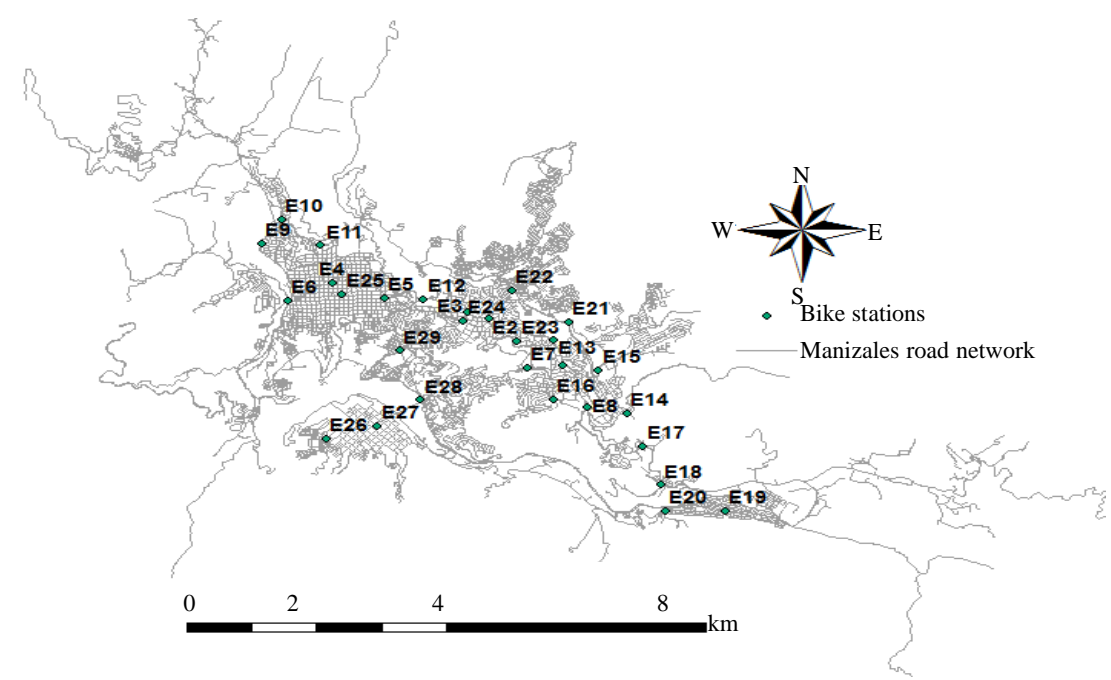

Fig. 3: Geographical bike station location first alternative 


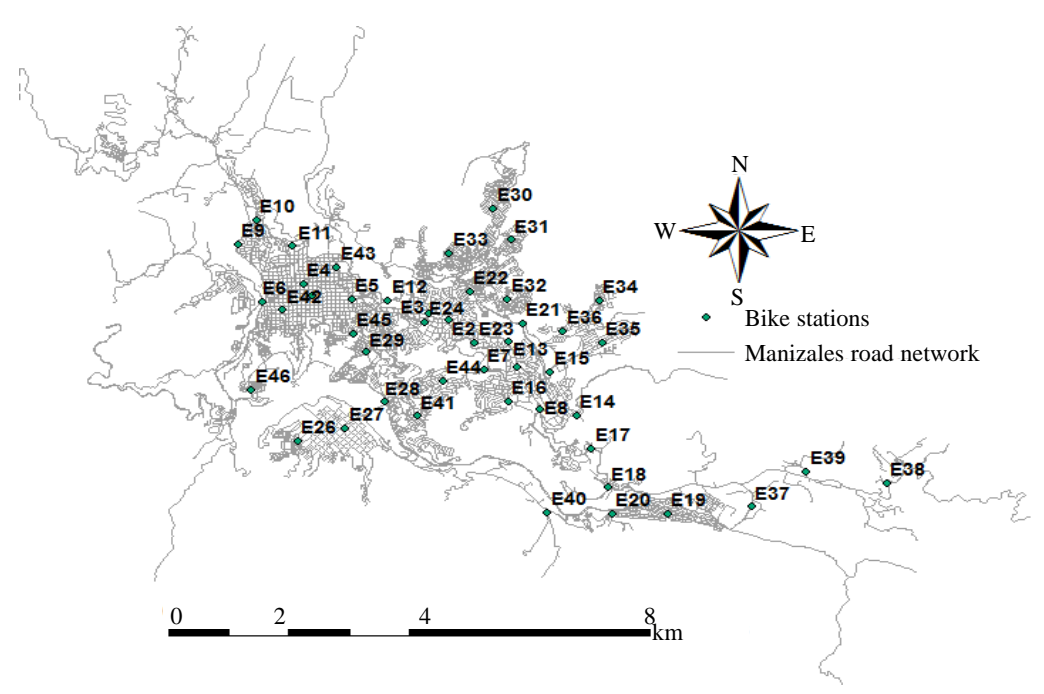

Fig. 4: Geographical bike station location second alternative researchers

Kawabata, 1998; Salonen and Toivonen, 2013), accessibility of each mode of transport(Eggermond and Earth, 2016; Farber and Marino, 2017), impacts on land-use(Geurs and Wee, 2004; Handy and Niemeier, 1997; Levinson and Krizek, 2005) and so on.

With regard to the social perspective, it is vital that people have access to different kind of activities, requiring excellent accessibility and provision of a high standard quality of means of transport through suitable transport systems (Farrington and Farrington, 2005). In the case of bike sharing systems, the access to a bike station is paramount to develop it successfully, increasing the number of daily trips (Kabra et al., 2015).

There are two different types of accessibility analysis to consider when the whole system is evaluated: passive and active accessibility (Cascetta et al., 2013); passive accessibility evaluates how many users could reach a specific location for example the closeness connectivity to a bike station (Garcia-Palomares et al., 2012) and active accessibility describes how many destinations can be reached by population in a timeframe using a mode of transportation in our case the system performance using public bikes (Cardona et al., 2017).

According to ITDP guide (Gauthie et al., 2013), there are three variables to evaluate an optimal planning of a bike sharing system:

- The minimum coverage of a bike sharing system has to be $10 \mathrm{~km}^{2}$, highlighting that each station influences $500 \mathrm{~m}$ round

- Number of bikes per 1000 residents. It has been estimated that between 10 and 30 bikes is an optimal value

- Station density should be a value between 10 and 16 stations $/ \mathrm{km}^{2}$

\section{MATERIALS AND METHODS}

The methodology used in this research is made up of 5stages: first, Manizale's transport network was updated for accuracy in the model development whereas the data related with the operational features of the network was analyzed and determined the second stage consisted in defining the operational walking speed in the network. The third stage is related with the calculation of the integral accessibility to each bike station from any point of the city in the current situation and two proposals in this stage the rule of the ITDP guide is used which express that each station influences $500 \mathrm{~m}$ round (Gauthie et al., 2013). The four stage concerns with the calculation of travel time saved in terms of percentage due to the new proposals. The fifth and last stage concerns the estimation of the percentages of population of each stratum covered by the average travel time curves.

Updating the transport network and the new proposals: The principal tool to develop accessibility models is a transport network, composed of nodes and arcs nodes represent the intersections and arcs represent road segments in which the average speed is loaded. In some cases, additional nodes are located to improve the interpolation of data.

Manizale's transport network was created in the Transport Master Plan of the city in 2010 (Anonymous, 2010) and it was updated, based on official documents like Alcaldía de Manizale's aerial photo, google maps, street view and open street maps.

Manizales en Bici was planned without demand studies and its bike stations were implanted intuitive in places where people usually go in a daily basis. For the 
first proposal, the preview approach was the main tool several crowding places were used to defined new stations. The 29 bike stations ( 8 current stations and 21 new stations) were implanted, increasing in $262.5 \%$ the number of stations in the system (For the second proposal, new bike stations in residential land were used, based on the experience as a citizen. The 46 bike stations (8 current stations and 36 new stations) were implanted, increasing in $475 \%$ the number of stations in the system (Operational speeds definition).

The operational speed was stored in the road segments as it provides information to calculate the travel time in the arcs. Particularly, theoretically walking speed is defined. Previous research showed that average walking speed is about $4.32 \mathrm{~km} / \mathrm{h}$ and is affected by the network slope $0.36 \mathrm{~km} / \mathrm{h}$ for $10 \%$ (Prada et al., 2008).

For the second proposal, new bike stations in land were used, based on the experience as a citizen. The 46 bike stations ( 8 current stations and 36 new stations) were implanted increasing in $475 \%$ the number of stations in the system (Operational speeds definition.

The operational speed was stored in the road segments as it provides information to calculate the travel time in the arcs. Particularly, theoretically walking speed is defined. Previous research showed that average walking speed is about $4.32 \mathrm{~km} / \mathrm{h}$ and is affected by the network slope $0.36 \mathrm{~km} / \mathrm{h}$ for $10 \%$ (Prada et al., 2008).

Operational speeds definition: The operational speed was stored in the road segments as it provides information to calculate the travel time in the arcs. Particularly, theoretically walking speed is defined. Previous research showed that average walking speed is about $4.32 \mathrm{~km} / \mathrm{h}$, and is affected by the network slope; $0.36 \mathrm{~km} / \mathrm{h}$ for $10 \%$ (Prada et al., 2008).

Estimating the integral accessibility: The passive or integral accessibility measures the interconnection between a particular node to the whole network. An algorithm of TransCAD® software was used to estimate the shortest path between a specific node and the others nodes, getting a matrix which contains the minimum average travel time of each node. This algorithm is known as Dijkstra algorithm (Dijkstra, 1959). Afterwars, the average travel time vector was calculated (Eq. 1):

$$
T_{v i}=\frac{\sum_{j=1}^{m} t_{v i}}{n-1} i=1,2,3, \ldots, n ; j=1,2,3, \ldots, m
$$

Where:

$\mathrm{T}_{\mathrm{vi}}=$ Minimum average travel time between node I and the others nodes in the network $\mathrm{t}_{\mathrm{vi}}=$ Minimum travel time between node $\mathrm{I}$ and node $\mathrm{J}$

$\mathrm{n}=$ Number of nodes in the network

The average travel time vector $(\mathrm{n} \times 1)$ is associated with the geographical coordinates (latitude and longitude) of each node. This vector represents the observations in the field, so that, it is essential to create a model to estimate the travel time in sectors where speed data is missing. Kriging Method is a spatial prediction method that includes autocorrelation, funded in minimizing the quadratic error of prediction (Giraldo, 2002); Kriging assumes that the distance between sample points shows spatial correlation. Kriging was used with linear semivariograms as a time prediction prototype for average trips.

Coverage analysis: The fifth and last stage is concerned about comparing the results of the previews stages with socio-demographic data provided by the local authorities. The city registers 415.124 inhabitants by 2015 with 97.666 households. The data provided was matched with the isochrones curves estimated with the model, finding the relation between the geographical location of the bike stations and the socio-demographic features of Manizales.

\section{RESULTS AND DISCUSSION}

Current situation: Figure 5 shows the isochrones curves to bike stations within $500 \mathrm{~m}$. People need to invest between $0 \mathrm{~min}$ (Green color) and $13 \mathrm{~min}$ (Red color) to get to any station the left side of the figure suggests more covered area due to a rolling terrain whilst the ride side has a mountainous terrain.

With regard to the spatial coverage to each stratum, Fig. 6, shows three groups; group 1 represents stratum four which is the best covered with the stations group 2 which is conformed by stratum 3,5 and 6 and group 3 which represents stratum 2 . It is highly noted that stratum 1 is not covered by the bike stations. To cover $50 \%$ of population of stratum 4 , it is invested 5 minutes, almost 6 minutes to cover the $50 \%$ of population of stratum 3,5 and 6 and more than $6 \mathrm{~min}$ to cover the $50 \%$ of population of stratum 2 .

First alternative: Figure 7 shows the isochrones curves to bike stations within $500 \mathrm{~m}$ in the first proposal. People need to invest between $0 \mathrm{~min}$ (Green color) and $20 \mathrm{~min}$ (Red color) to get to any station. In spite of increasing the travel time to get to any station, the coverage has increased as well and more population could use the system. It is highly noted that the aerial cableway gives a connection between stations, creating a multimodal system. 


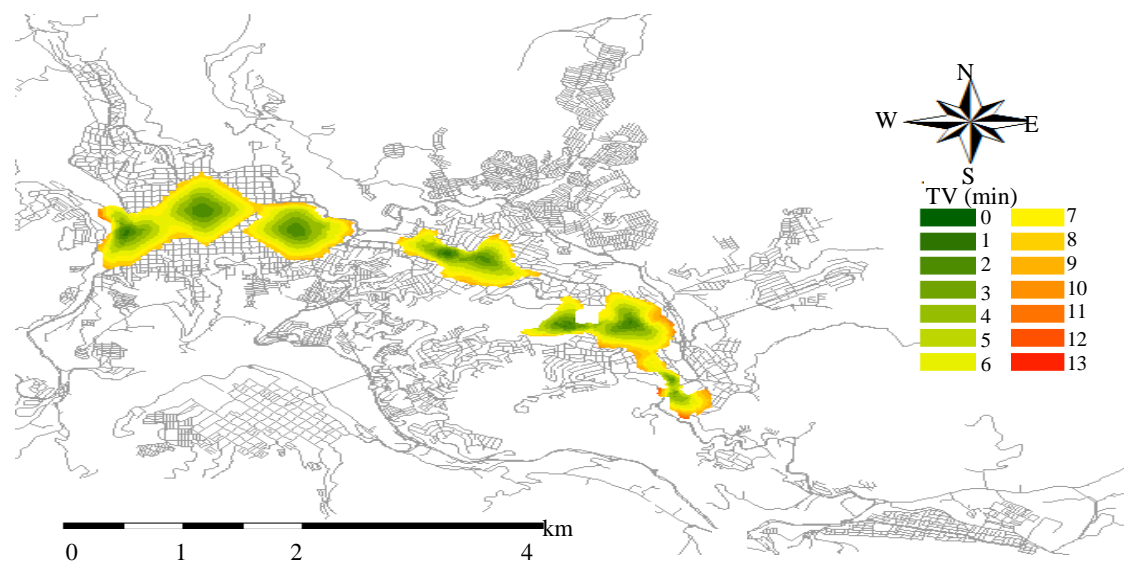

Fig. 5: Isochrones curves to bike stations within $500 \mathrm{~m}$ current situation researchers

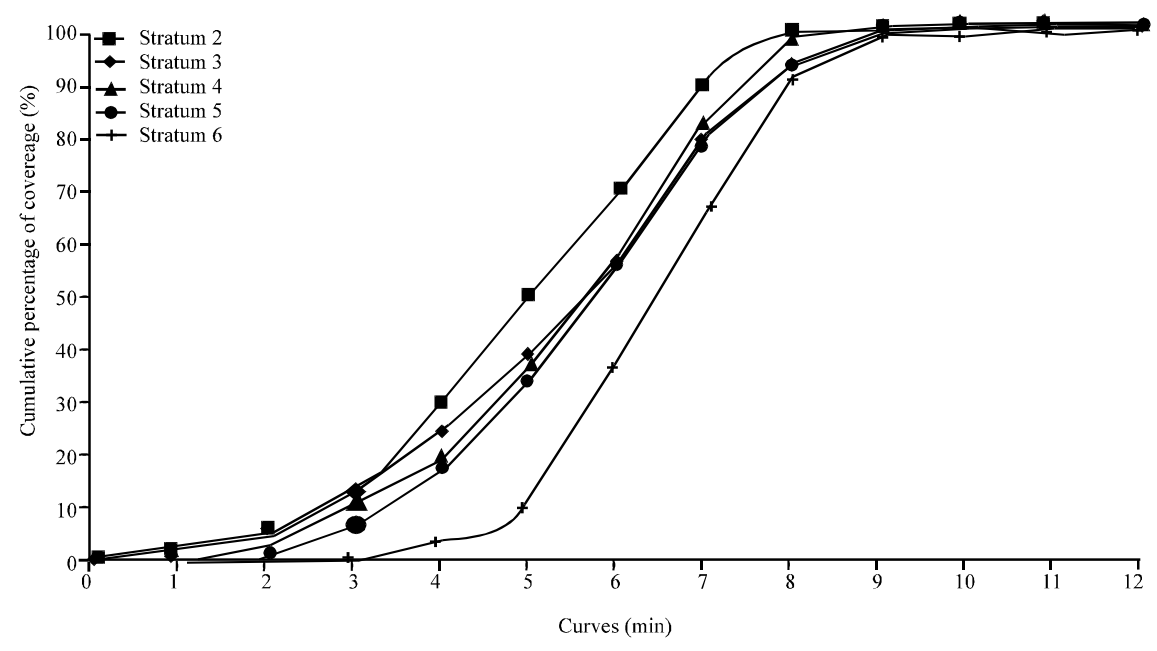

Fig. 6: Cumulative percentage of coverage current situation researchers

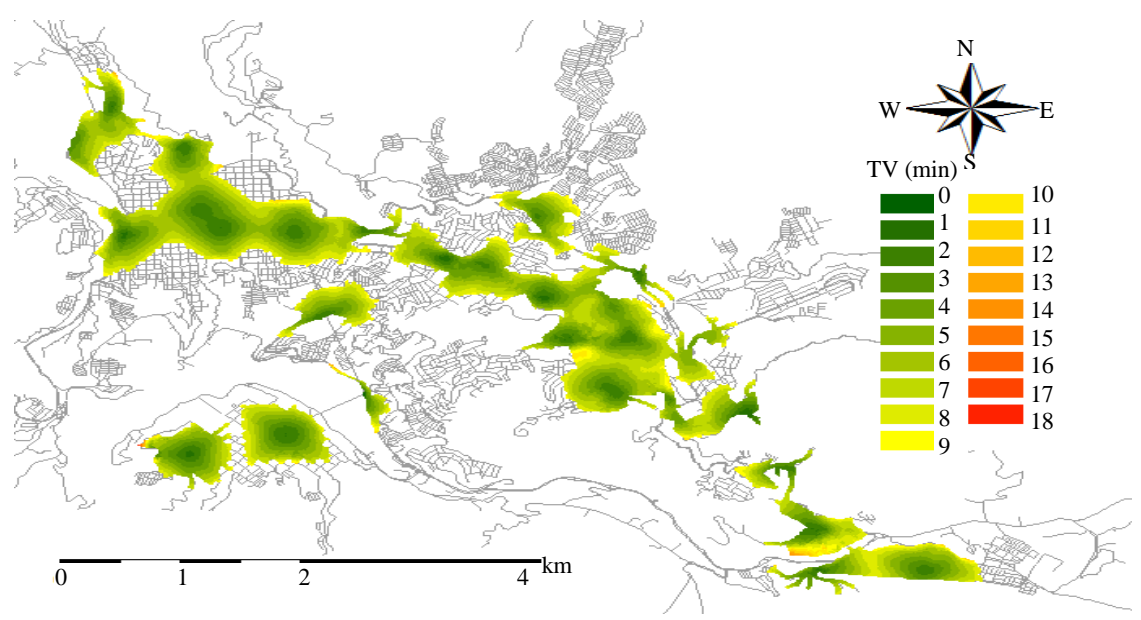

Fig. 7: Isochrones curves to bike stations within $500 \mathrm{~m}$ first alternative researchers 


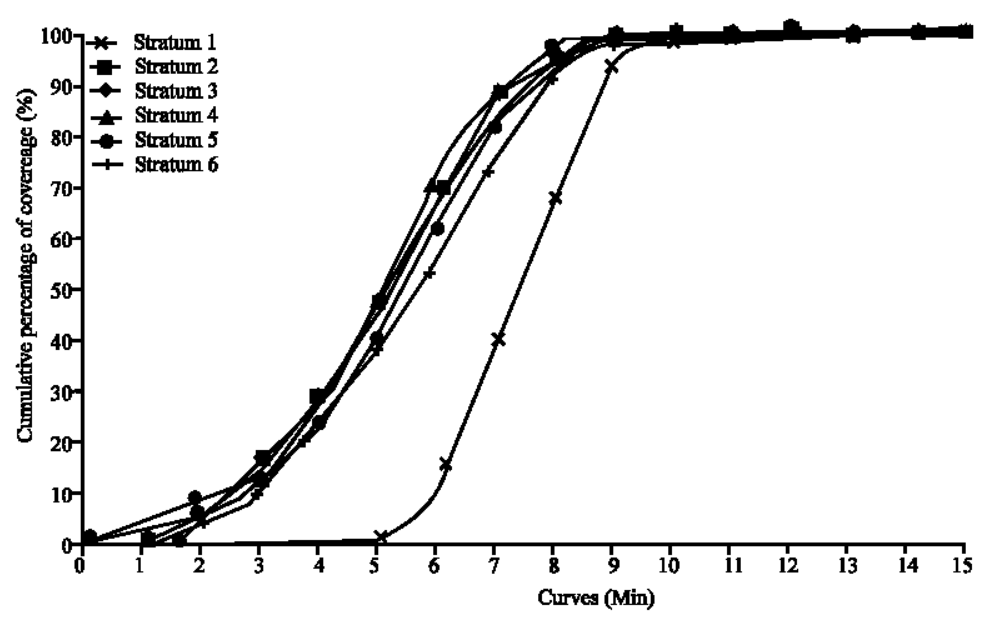

Fig. 8: Cumulative percentage of coverage first alternative researchers

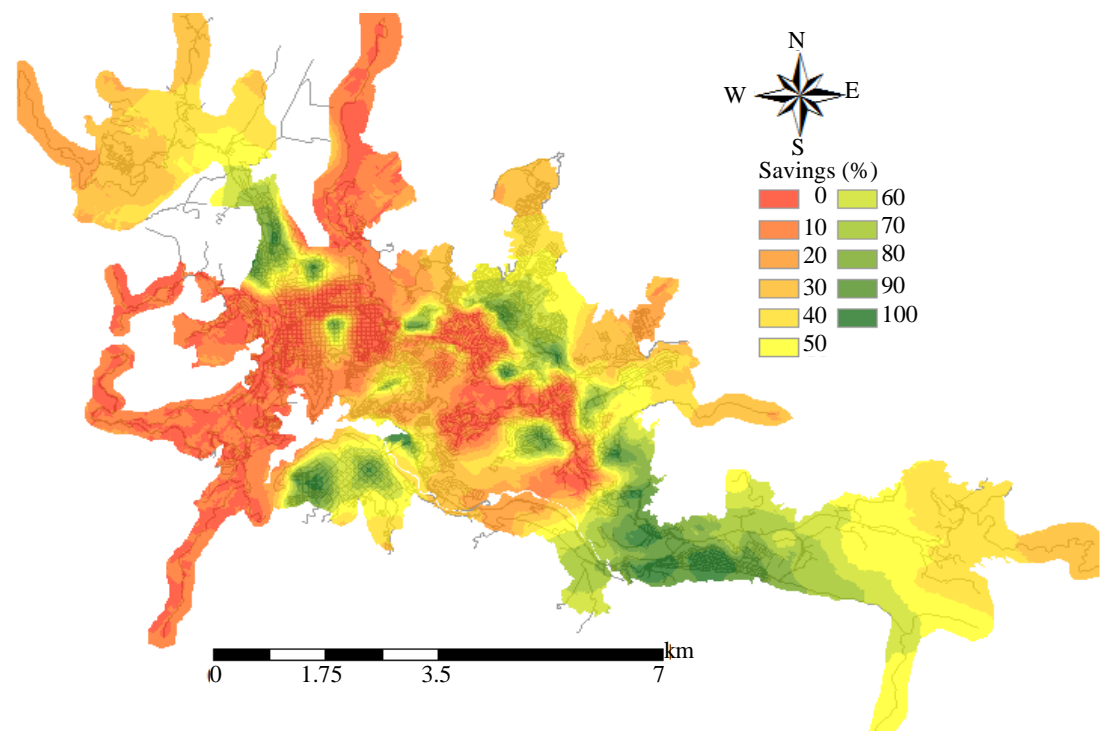

Fig. 9: Percentage of savings in travel time first alternativen researchers

With regard to the spatial coverage to each stratum, Fig. 8, shows that stratum 1 is the less covered. It is required to invest between 7 and $8 \mathrm{~min}$ to cover $50 \%$ of population for stratum 2 and 3 between 5 and $6 \mathrm{~min}$ is invested to cover $50 \%$ of population whilst for stratum 5 and 6 , the time to invest to cover $50 \%$ of population is about $5 \mathrm{~min}$. It is concluded, that the bike-sharing system benefits people of high strata and as a transport policy, it offers an alternative mode of transport for people who usually use car.

Comparing this approach with the current situation, it is noted, according to Fig. 9, that the places where new bike stations are located showed almost $100 \%$ of saving in terms of travel time. In Fig. 10, it is showed that for 90\% of population, stratum 1,2 and 4 save $10 \%$ of time travel and stratum 3,5 and 6 save $5 ; 50 \%$ of population show almost $60 \%$ of savings in travel time for stratum $4 ; 42 \%$ stratum 2 and $6 ; 35 \%$ stratum 3 and $25 \%$ stratum 1 and 5 . For $10 \%$ of population, stratum 1 shows $60 \%$ of savings, $80 \%$ for stratum 2 and $5 ; 81 \%$ for stratum $4 ; 87 \%$ for stratum 6 and $90 \%$ for stratum 3 . Overall it is showed that stratum 4 is the best covered as it shows more savings in terms of travel time whilst stratum 1 is the less covered.

Second alternative: Figure 11 shows the isochrones curves to bike stations within $500 \mathrm{~m}$ in the second 


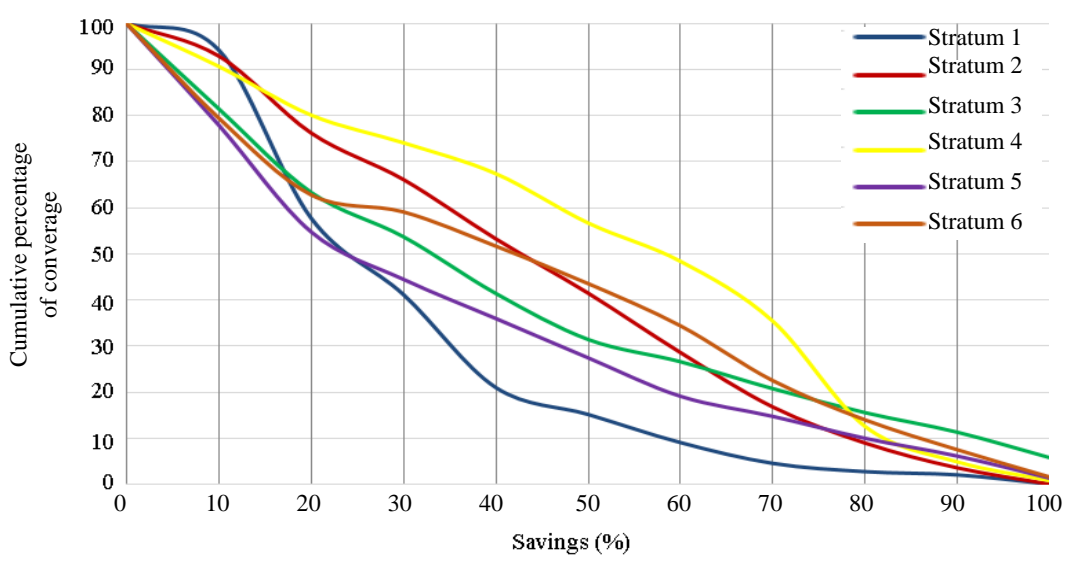

Fig. 10: Percentage of population with savings in travel time first alternative

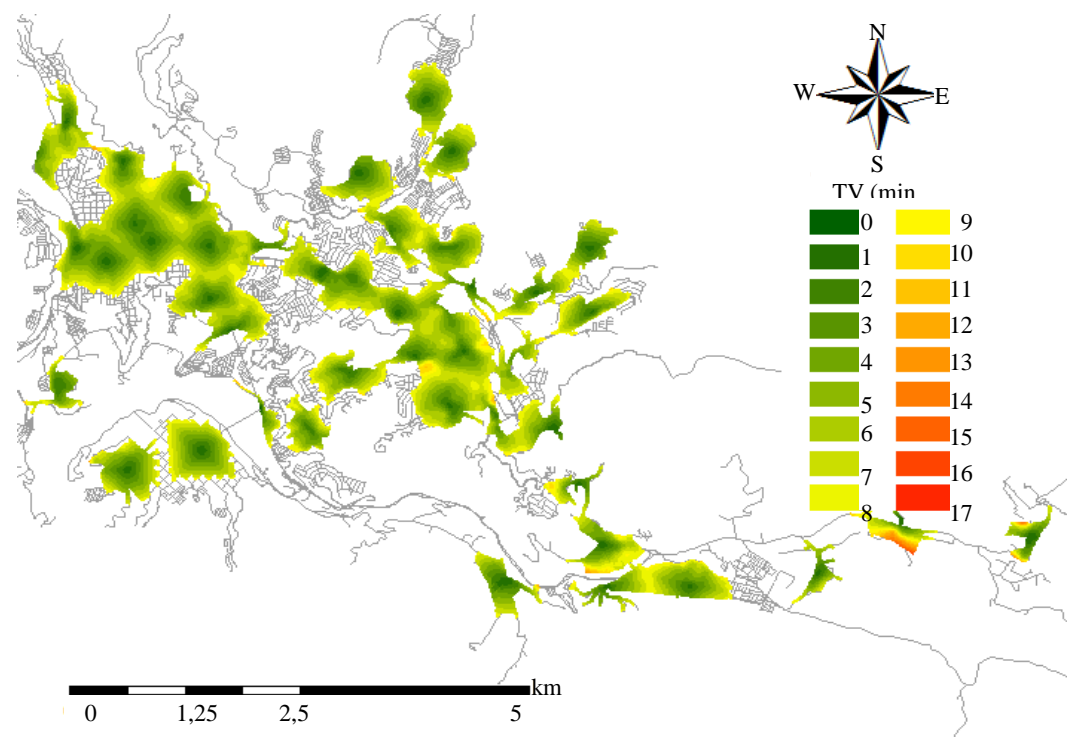

Fig. 11: Isochrones curves to bike stations within $500 \mathrm{~m}$ second alternative

proposal. People need to invest between 0 min (Green color) and $17 \mathrm{~min}$ (Red color) to get to any station this proposal shows the system performance if several stations were near to low stratum neighbors.

In Fig. 12, the coverage for each stratum is analysed. This proposal improves the equity between strata; Stratum 1 needs to invest $5.5 \mathrm{~min}$ for being covered the $50 \%$ of population whilst for the rest, it is need to invest $5 \mathrm{~min}$ to cover $50 \%$ of population the difference between stratum 1 and the rest is for $0.5 \mathrm{~min}$ which is a low value of time and shows equity.

Comparing this approach with the current situation, it is noted, according to Fig. 13 that, the places where new bike stations are located showed almost $100 \%$ of saving in terms of travel time. In Fig. 14, it is showed the cumulative percentage of coverage against percentage of savings in terms of travel time. For $90 \%$ of population, stratum 2 saves $35 \%$ of travel time $30 \%$ for stratum 1 and more of $10 \%$ for stratum 3 and 4 whilst in the firts proposal stratum 1,2 and 4 showed $10 \%$ of savings in terms of travel time and $5 \%$ for stratum 3 for $50 \%$ of population, stratum 4 saves almost $70 \%$ when in the first proposal showed $60 ; 75 \%$ for stratum 2 while in the first proposal showed $42 ; 65 \%$ for stratum 3 when $35 \%$ was saved in the first proposal and almost $50 \%$ for stratum 1 whilst in the first proposal showed $25 \%$. Overall, strata of low and medium income showed an increase in the savings whilst for high strata the percentage of savings remained steady.

\section{Comparisons of the proposals with the current situation:} In Fig. 15, the population covered in the current situation and the two proposals were compared, walking to the bike stations. To cover $50 \%$ of population within $500 \mathrm{~m}$ of 


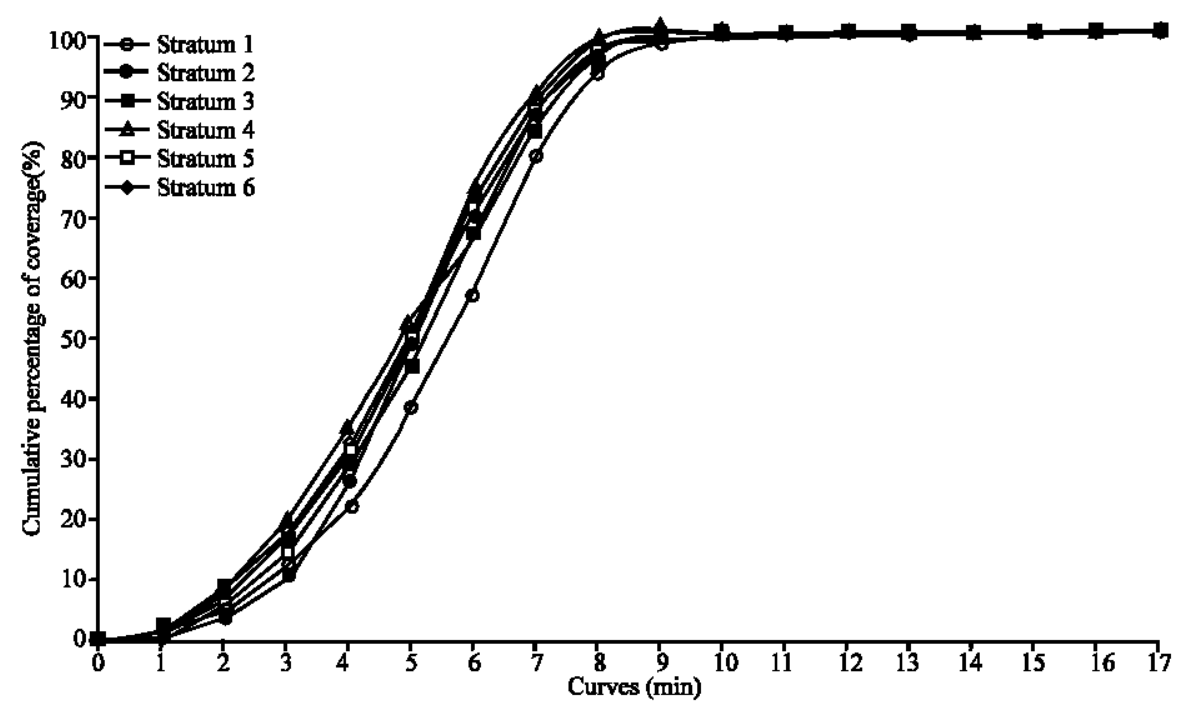

Fig. 12: Cumulative percentage of coverage second proposal

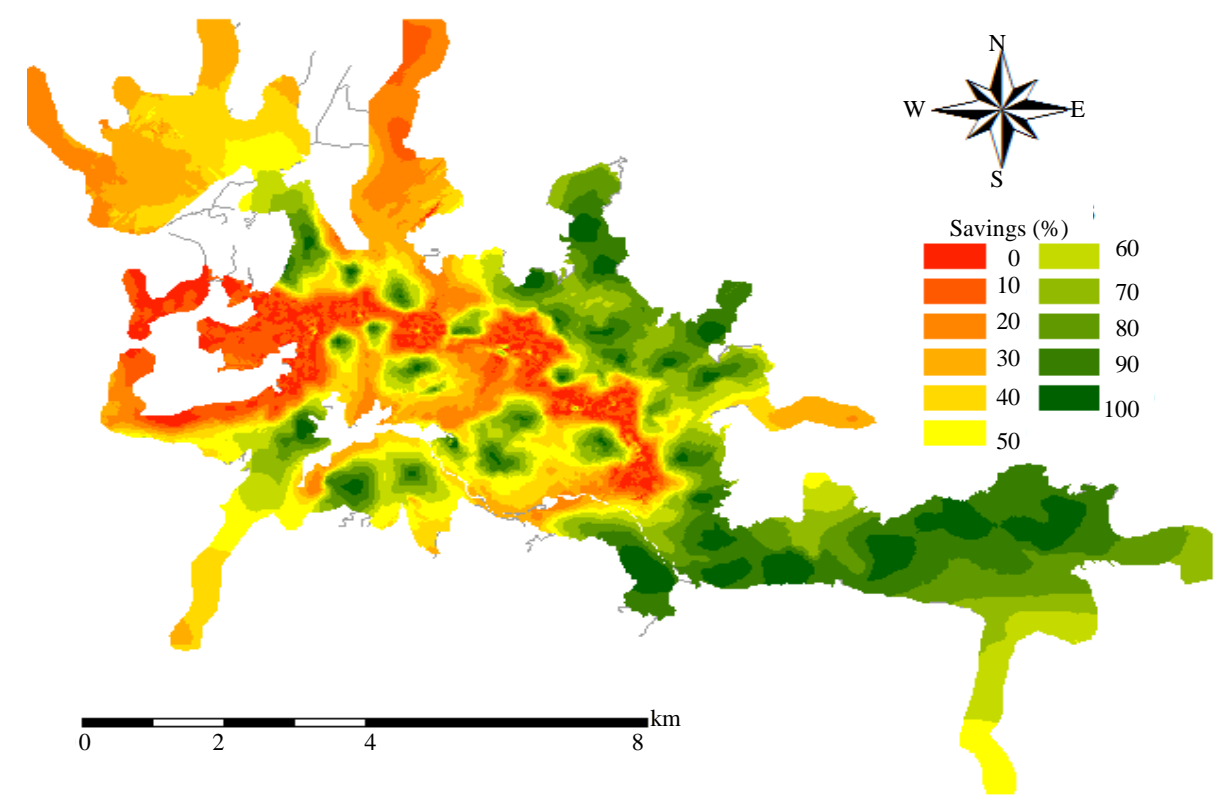

Fig. 13: Percentage of savings in travel time second alternative

influence (Gauthie et al., 2013) $5 \mathrm{~min}$ average is need to invest in the second proposals whilst in the first proposal and current situation, people need to invest $5.5 \mathrm{~min}$.

In Figure 16 Comparison of the percentage of population covered in the current situation and the two alternatives, walking to bike stations. The cumulative percentage of covered population in the two proposals versus the percentage of savings in terms of travel time. It is highly noted $90 \%$ of population has at least $10 \%$ of savings in the first proposal while in the second proposal, at least population has $15 \%$ of savings $50 \%$ of population has at least 40 and $67 \%$ of savings in the first and second proposals, respectively and $10 \%$ of population has at least $80 \%$ of savings in the first proposal whilst in the second proposal population has around $100 \%$ of savings in travel time.

This results show that the second proposal has more benefits than the first one. Increasing the number of stations increase the number of origins and destinations for people and reduce the time to access to the stations. 


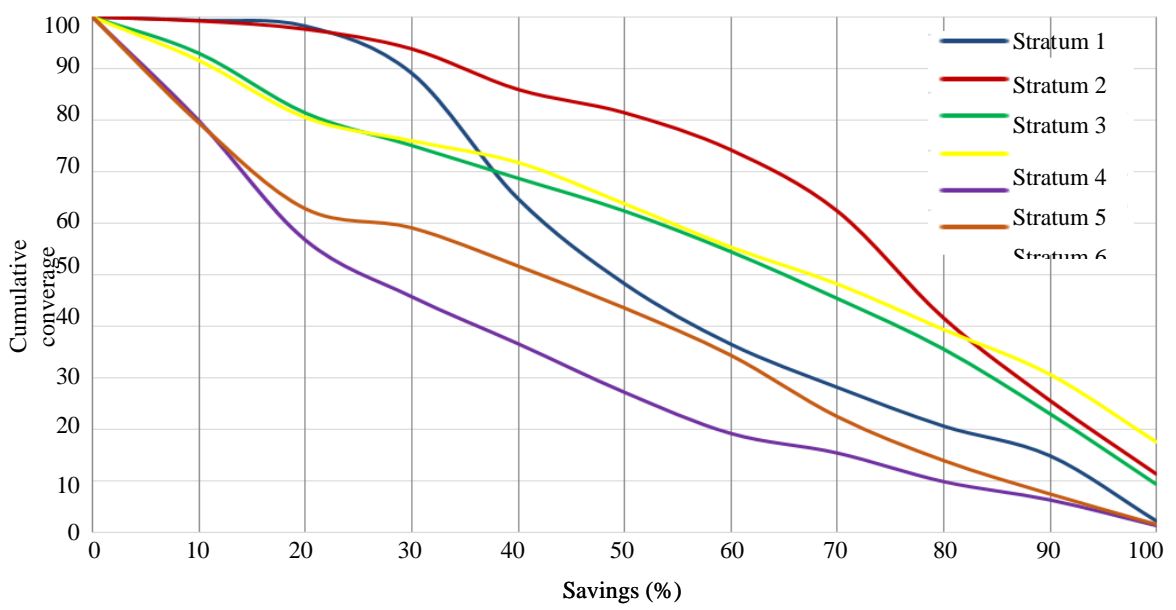

Fig. 14: Percentage of population with savings in travel time second alternative researcher

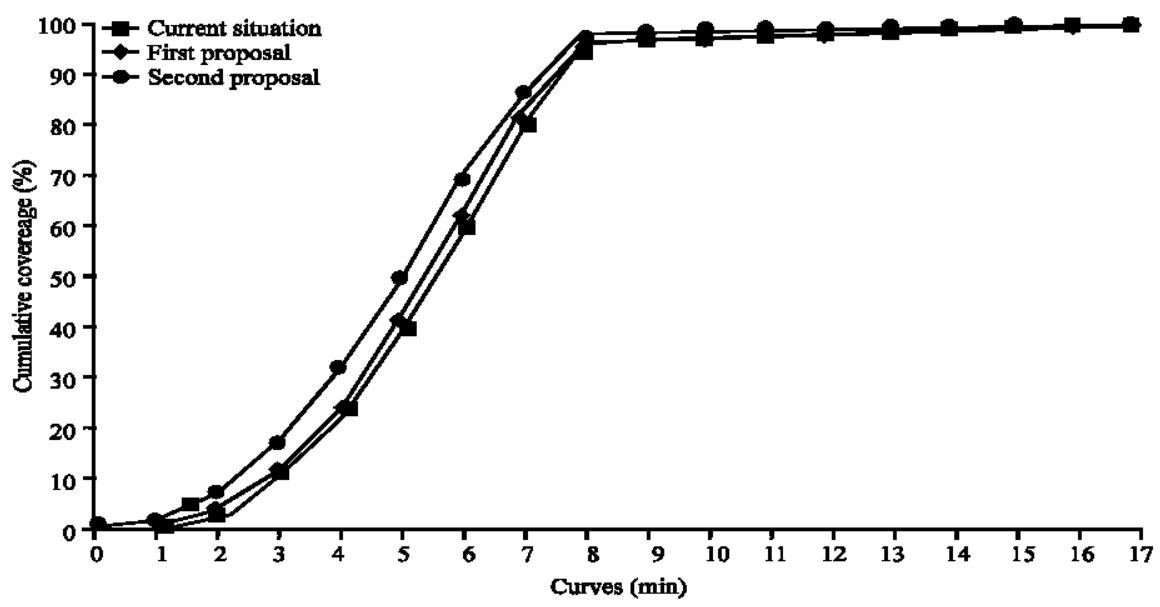

Fig. 15: Comparison of the percentage of population covered in the current situation and the two alternatives, walking to bike stations researcher

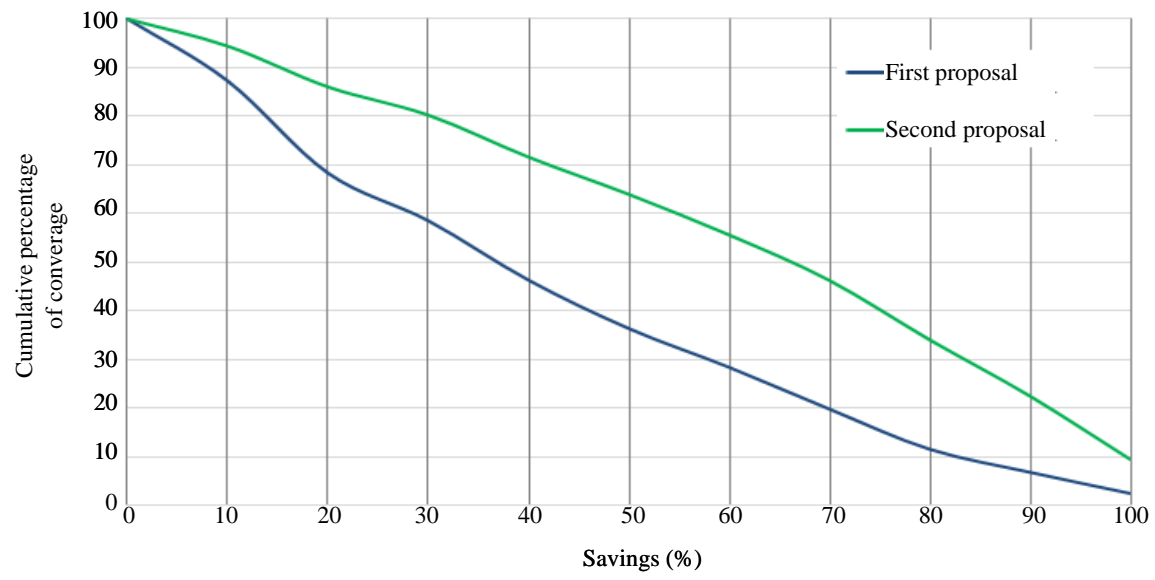

Fig. 16: Comparison of cumulative percentage of population covered by the proposals versus 


\section{CONCLUSION}

Current transport policies in developing countries have been using the car as a principal mode of transportation whilst several impacts as congestion, pollution, accidentalness have increased as well. Bike-sharing systems have become a sustainable and optimal mode to overcome those impacts in population and in the environment.

The primary goal to enhance bike users experience is increasing the number of bike stations as it increases the origins and destinations pairs that could be covered by the system. Accessibility models are a powerful tool to rise the coverage systems and analyse the positive impacts that could increase quality life for population. The results of this research indicates that increasing the number of stations could improve bike-sharing system performance. However, modelling demand behaviour must be done to optimize the location of new future stations. The fact that demand data is not available indicates that transport authority doesn't have the right tools to plan the transportation system and fulfil the population needs.

\section{LIMITATIONS}

This research was developed based on accessibility models which use supply characteristics of the transport network without taking account the demand behaviour. Now a days, Manizales administration is updating the $O-D$ matrix to diagnose people travel behaviour. For that reason, this research lack on specific demand analysis, and assumptions were made to finish completely the study.

\section{RECOMMENDATIONS}

In the future the O-D matrix of the city should be used to improve bike stations locations based on potential and current users. Furthermore, identifying the number of origins and destinations to reinforce the bike usage and reducing the car usage.

\section{ACKNOWLEDGEMENTS}

This research was conducted at National University of Colombia in Manizales campus through the National announcement of projects for the strengthening of the research, creation an innovation of the National University of Colombia 2016-2018. The researchers would like to thank DIMA for helping and motivating young researchers to develop new and technical studies for the benefit of the city. This research is part of a Master
Thesis called "Propuesta metodologica para el diagnóstico y planificacion urbana de una red de ciclorutas. Caso de estudio: Manizales.", Code: 35178 developed by the same researchers of this research.

\section{REFERENCES}

Anonymous, 2010. [Master mobility plan]. Infi-Manizales, Manizales, Colombia. (In Spanish) https://www.infimanizales.com/portfolio/plan-maest ro-de-movilidad/

Benenson, I., K. Martens, Y. Rofe and A. Kwartler, 2011. Public transport versus private car GIS-based estimation of accessibility applied to the Tel Aviv metropolitan area. Ann. Reg. Sci., 47: 499-515.

Broach, J., J. Dill and J. Gliebe, 2012. Where do cyclists ride? A route choice model developed with revealed preference GPS data. Transp. Res. Part A Policy Pract., 46: 1730-1740.

Brocker, J., A. Korzhenevych and C. Schurmann, 2010. Assessing spatial equity and efficiency impacts of transport infrastructure projects. Trans. Res. Part B: Methodol., 44: 795-811.

Cardona, M., J. Zuluaga and D. Escobar, 2017. [Analysis of the cycle-route network of Manizales (Colombia) based on criteria of urban territorial accessibility and coverage of socioeconomic strata]. Rev. Espacios, 38: $1-11$.

Cascetta, E., A. Cartenui and M. Montanino, 2013. A new measure of accessibility based on perceived opportunities. Procedia Soc. Behav. Sci., 87: 117-132.

Cheng, J., L. Bertolini and F.I. Clercq, 2007. Measuring sustainable accessibility. Transp. Res. Rec.: J. Transp. Res. Board, 2017: 16-25.

Dijkstra, E.W., 1959. A note on two problems in connexion with graphs. Numerische Mathematik, 1: 269-271.

Eggermond, M.A.V. and A. Erath, 2016. Pedestrian and transit accessibility on a micro level: Results and challenges. J. Transp. Land Use, 9: 127-143.

Farber, S. and M.G. Marino, 2017. Transit accessibility, land development and socioeconomic priority: A typology of planned station catchment areas in the Greater Toronto and Hamilton Area. J. Transp. Land Use, 10: 33-56.

Farrington, J.H. and C.J.T. Farrington, 2005. Rural accessibility, social inclusion and social justice: Towards conceptualization. J. Transp. Geogr., 13: $1-12$. 
Frade, I. and A. Ribeiro, 2015. Bike-sharing stations: A maximal covering location approach. Transp. Res. Part A Policy Pract., 82: 216-227.

Garcia-Palomares, J.C., J. Gutierrez and M. Latorre, 2012. Optimizing the location of stations in bike-sharing programs: A GIS approach. Appl. Geogr., 35: 235-246.

Gauthie, A., C. Hughes, C. Kost, S. Li and C. Linke et al., 2013. [Public bicycle system planning guide]. Institute for Transportation and Development Policy, New York, USA. (In Spanish) http://mexico.itdp.org/documentos/guia-de-planeac ion-del-sistema-de-bicicleta-publica/

Geurs, K.T. and B.V. Wee, 2004. Accessibility evaluation of land-use and transport strategies: Review and research directions. J. Transp. Geog., 12: 127-140.

Geurs, K.T. and J.R.R.V. Eck, 2001. Accessibility measures: Review and applications evaluation of accessibility impacts of land-use transport scenarios and related social and economic impacts. Netherlands National Institute for Public Health and the Environment, Netherlands, Europe. https://www.rivm.nl/bibliotheek/rapporten/4085050 06.pdf.

Giraldo, R., 2002. [Introduction to Geostatistics Theory and Application]. National University of Colombia, Bogota, Colombia, (In Spanish).

Gutierrez, J., A. Condeco-Melhorado and J.C. Martin, 2010. Using accessibility indicators and GIS to assess spatial spillovers of transport infrastructure investment. J. Transp. Geogr., 18: 141-152.

Handy, S.L. and D.A. Niemeier, 1997. Measuring accessibility: An exploration of issues and alternatives. Environ. Plann. A, 29: 1175-1194.

Hansen, W.G., 1959. How accessibility shapes land use. J. Am. Inst. Plann., 25: 73-76.

Hughes, H.L., 1993. Metropolitan structure and the suburban hierarchy. Am. Sociological Rev., 58: 417-433.

Jaramillo, C., C. Lizarraga and A.L. Grindlay, 2012. Spatial disparity in transport social needs and public transport provision in Santiago de Cali (Colombia). J. Transp. Geogr., 24: 340-357.

Jiang, H. and D. Levinson, 2017. Accessibility and the evaluation of investments on the Beijing subway. J. Transp. Land Use, 10: 395-408.

Kabra, A., E. Belavina and K. Girotra, 2015. Bike-share systems: Accessibility and availability. Master Thesis, Booth School of Business, Chicago, Illinois.

Kawabata, M., 1998. User-equilibrium properties of fixed points in dynamic traffic assignment. Transp. Res. Part C Emerging Technol., 41:
Kotavaara, O., H. Antikainen and J. Rusanen, 2011. Population change and accessibility by road and rail networks: GIS and statistical approach to Finland 1970-2007. J. Trans. Geogr., 19: 926-935.

Levinson, D.M. and K.J. Krizek, 2005. Access to Destinations. Elsevier, Amsterdam, Netherlands, ISBN:9780080446783, Pages: 414.

MacKinnon, D., G. Pirie and M. Gather, 2008. Transport and Economic Development. Wiley-Blackwell, Hoboken, New Jersey, USA., ISBN: 9781405153225 ,

Papa, E., C. Silva, M. Te Brommelstroet and A. Hull, 2016. Accessibility instruments for planning practice: A review of European experiences. J. Transp. Land Use, 9: $57-75$.

Prada, L., N. Laurents and S. Cristancho, 2008. [Practical Guide to Urban Pedestrian Mobility]. Bogota, Santa Fé de Bogota, Colombia, (In Spanish).

Ribeiro, A. and J. Silva, 2011. Space, development and accessibility between Portugal and Spain: The last frontier. Rev. Portuguesa Estudos Regionais, 27: 7-14.

Rietveld, P. and P. Nijkamp, 1992. Transport and Regional Development. VU University Amsterdam, Amsterdam, Netherlands,

Rybarczyk, G. and C. Wu, 2010. Bicycle facility planning using GIS and multi-criteria decision analysis. Applied Geogr., 30: 282-293.

Salonen, M. and T. Toivonen, 2013. Modelling travel time in urban networks: Comparable measures for private car and public transport. J. Transp. Geogr., 31: 143-153.

Shaheen, S., S. Guzman and H. Zhang, 2010. Bikesharing in Europe the Americas and Asia: Past, present and future. Transp. Res. Rec. J. Res. Board, 2143: 159-167.

Spiekerman, K. and J. Neubauer, 2002. European accessibility and pheripherality: Concepts, models and indicators. Stockholm, Sweden http://www.nordregio.se/Global/Publications/Publi cations \%202002/WP2002_9.pdf.

Suarez-Vega, R., D.R. Santos-Penate and P. Dorta-Gonzalez, 2012. Location models and GIS tools for retail site location. Applied Geogr., 35: 12-22.

Vickerman, R., K. Spiekermann and M. Wegener, 1999. Accessibility and economic development in Europe. Reg. Stud., 33: 1-15.

Wang, J., C.H. Tsai and P.C. Lin, 2016. Applying spatial-temporal analysis and retail location theory to public bikes site selection in Taipei. Transp. Res. Part A Policy Pract., 94: 45-61. 